\title{
KARAKTERISTIK DAN DESKRIPSI ORDO PASSERIFORMES DI JALAN SENIMAN AMRI YAHYA JAKABARING PALEMBANG SUMATERA SELATAN
}

\author{
Syahirul Alim ${ }^{1}$, Syaiful Eddy ${ }^{2}$, Dian Mutiara ${ }^{3}$ \\ ${ }^{1,2,3}$ Program Studi Biologi, Fakultas Matematika dan Ilmu Pengetahuan Alam \\ Universitas PGRI Palembang \\ e-mail : alimsyahirul390@gmail.com
}

\begin{abstract}
Research on the Characteristics and Descriptions of the Order of Passeriformes has been carried out on Jalan Seniman Amri Yahya Jakabaring, Palembang South Sumatara The research aims to determine the Familia, Genus, and Species of the Order Paseriformes and How the Characteristics and Descriptions of the Passeriformes Order on Jalan Seniman Amri Yahya Jakabaring Palembang, South Sumatra. The study was conducted in March-April 2020. Observations were made in the morning (06.00 - 09.00 WIB) and afternoon (15.00 - 18.00 WIB). The method used is the point count method modified from Yustian et al., (2017). Observations were made by observing birds in the form of bird morphology, locomotor (in the form of legs and wings) and bird's head as well as colors. Every bird that was observed was taken the picture. Identified with the 2010 Mackinnon Field Guide book. The results of the study were obtained by the Order of Passeriformes with 7 families of 10 Genera and 14 Species. Characteristics Morphological features include relatively short foot shape with anisodactyl toe type, ie three fingers facing forward and one finger facing back. The puppies of birds in this order are altricial, that is, they are helpless when they hatch (blind, without feathers, and rarely move). The birds of this order include birds chirping have a beautiful voice.
\end{abstract}

Keywords: Aves, Description of aves, Characteristics of aves, OrderPasseriformes.

\begin{abstract}
ABSTRAK
Telah dilakukan Penelitian Karakteristik dan Deskripsi Ordo Passeriformes di jalan Seniman Amri Yahya Jakabaring Palembang Sumatara Selatan. Penelitian bertujuan untuk mentukan Familia, Genus, dan Spesies dari Ordo Paseriformes dan Bagaimana Karakteristik dan Deskripsi Ordo Passeriformes di Jalan Seniman Amri Yahya Jakabaring Palembang Sumatera Selatan. Penelitian di lakukan bulan Maret-April 2020. Pengamatan dilakukan Pada pagi (Pukul 06.00 - 09.00 WIB) dan sore (Pukul 15.00 - 18.00 WIB). Metode yang digunakan yaitu metode titik hitung (point count) yang di modifikasi dari Yustian et al., (2017). Pengamatan dilakukan dengan mengamati burung yang hingap berupa morfologi burung, alat gerak (berupa kaki, dan sayap) dan kepala burung juga warna. Setiap burung yang diamati diambil gambarnya. Di Identifikasi dengan buku Panduan lapangan Mackinnon 2010. Hasil penelitian di dapat Ordo Passeriformes dengan 7 familia 10 Genus dan 14 Spesies. Karakteritik Ciri morfologinya diantaranya bentuk kaki yang relatif pendek dengan tipe jari kaki anisodactyl, yakni tiga jari menghadap ke depan dan satu jari menghadap ke belakang. Anakan burung pada ordo ini bersifat altricial, yakni tidak berdaya ketika menetas (buta, tanpa bulu, dan jarang bergerak), Burung-burung dari ordo ini meliputi burung pengicau memiliki suara yang indah.
\end{abstract}

Kata kunci :Aves, Deskripsi aves, Karakteritik aves, Ordo Passeriformes. 


\section{PENDAHULUAN}

Burung (Aves) adalah salah satu jenis satwa yang sangat terpengaruh keberadaannya akibat alih guna lahan hutan, terutama pada lahan-lahan monokultur seperti perkebunan kelapa sawit dan karet. Hilangnya pohon hutan dan tumbuhan semak, menyebabkan hilangnya tempat bersarang, berlindung dan mencari makan berbagai jenis burung. Berbagai jenis burung dapat kita jumpai di berbagai tipe habitat, diantaranya hutan (primer atau sekunder), agroforest, perkebunan (sawit, karet, dan kopi) dan tempat terbuka (pekarangan, sawah, lahan terlantar) (Ayat, 2011).

Menurut Iqbal et al., (2016a), Hutan Rekreasi Punti Kayu adalah hutan pinus buatan yang dirancang sebagai paru-paru dan taman di Kota Palembang. Burungburung yang dicatat pada Punti Kayu dikaji untuk melihat pentingnya hutan untuk habitat alami burung. Sebanyak 44 spesies dari 24 familia burung. Salah satu habitat yang disukai burung, terutama unggas air. jenis burung yang ditemukan di area budidaya udang intensif. Keberadaan burung terdapat pada dua kolam intensif yaitu Sumatra Selatan dan Lampung. Hasil menunjukkan bahwa tingkat keanekaragaman burung di dua kolam intensif berkisar dari sedang hingga tinggi di 2,90 untuk kolam intensif di Sumatera Selatan dan 3:55 untuk kolam intensif di Lampung. Kolam menjadi salah satu tempat paling penting bagi burung, tetapi karena memiliki keanekaragaman spesies yang tinggi, kolam juga menjadi salah satu habitat atau lokasi singgah burung migrant (Master et al., 2016 ),

Menurut Iqbal et al., (2016b), Survei burung cepat dilakukan di kawasan konservasi kecil konsesi kayu industri PT BMH (Bumi Mekar Hijau), yaitu KPPN (Kawasan Pelestarian Plasma Nutfah), Provinsi Sumatera Selatan. Daerah ini memiliki 448 ha, didominasi oleh hutan rawa sekunder yang rusak dikelilingi oleh perkebunan Acacia. Dapat di temukan Sebanyak 36 spesies, spesies burung (29 spesies), diikuti oleh rekaman stasiun audiovisual (26 spesies) dan mist-netting (tiga spesies). Ada delapan spesies yang dilindungi oleh hukum Indonesia dan dua burung terdaftar sebagai Near Threatened (NT) oleh International Union for Conservation of Nature atau IUCN. Meskipun jumlah spesies burung yang dicatat tidak signifikan, tetapi daerah ini masih mendukung habitat untuk berbagai keanekaragaman burung, dan hutan yang tersisa harus dikelola dengan baik untuk mendukung tujuan konservasi.

Ordo Passeriformes merupakan jenis aves kosmolopit, yang mana penyebarannya pada hanbitat yang luas. kerabat Passeriformes diantaranya seperti burung gereja dan pipit, salah satu aves yang mudah ditemui disekitar. Kerabat Passeriformes burung juga sering ditemui di hutan sekunder seperti semak belukar contohnya cucak kutilang. Ordo Passeriformes juga dikenal sebagai Aves pekicau dan bernilai ekonomi seperti cucak kutilang dan merba belukar. Aves di Jalan Seniman Amri Yahya Jakabaring Palembang Sumatera Selatan banyak bertengger, terbang, keluar dari semak belukar karena pohon bunggur tempat berlindung aves ordo Passeriformes di dekat pepohanan ini juga ada sumber ada anak sungai tempat aves-aves ini minum dan mencari makan di pohon.

Jenis aves di Pulau Sumatera dan Indonesia, kawasan agroforest di Sumatera memiliki 49,8\% dari jenis aves Sumatera dan 18,8\% dari jenis burung di Indonesia (Ayat, 2011). Indonesia merupakan negara mega biodiversitas yang menempati urutan kedua sebagai negara dengan tingkat biodiversitas atau keanekaragaman hayati yang tinggi. Salah satu keanekaragaman hayati yang dimiliki Indonesia berupa avifauna (burung). Keanekaragaman aves di Indonesia mencapai 1.771 spesies (Burung Indonesia.org, 2018 ).

Aves merupakan salah satu komponen ekosistem yang berperan sangat penting dalam mendukung kelangsungan siklus 
organisme. Hal ini dapat dilihat dari rantai makanan yang membentuk sistem kehidupan dengan komponen ekosistem lainnya, yakni tumbuhan dan serangga. (MacKinnon et al., 2010). Sebagai salah satu contoh yang terjadi di Sumatera Selatan belakangan ini, kondisi hutan yang beralih fungsi berdampak terhadap berkurangnya luas hutan produksi. Penebangan hutan juga merupakan salah satu penyebab hilangnya tempat bersarang, berlindung dan mencari makan bagi burung.

Berdasakan survei awal dan informasi dari masyarakat terdapat keanekaragaman jenis burung tersebut. Selama ini belum ada penelitian yang melaporkan tentang jenisjenis aves dari Ordo Passeriformes di Jalan Seniman Amri Yahya Jakabaring Palembang Sumatera Selatan.

\section{METODE DAN ALAT}

Penelitian Karakteristik dan Deskripsi Ordo Passeriformes akan dilakukan di Jalan Seniman Amri Yahya Jakabaring Palembang Sumatera Selatan. Penelitian dilakukan Selama 3 minggu Maret-April 2020.

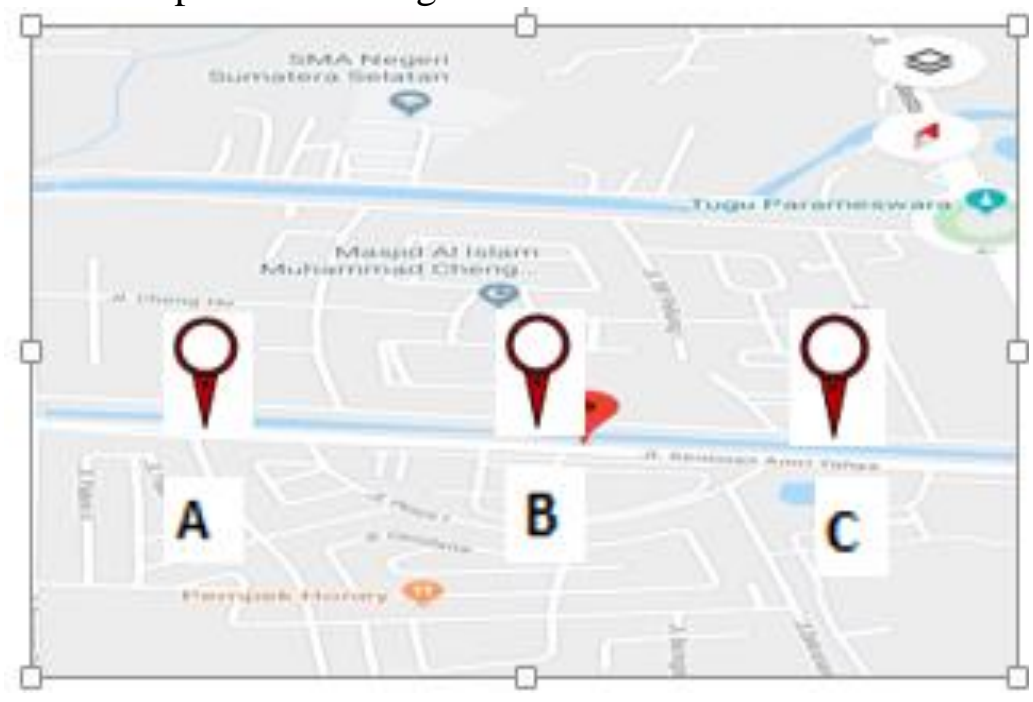

Gambar 1. Peta lokasi pengamatan

(Sumber : Googgle maps.2020)

Alat dan bahan yang digunakan yaitu teropong 8x aut $988000 \mathrm{~m}$, dan Teleskop 40x60 (1500 m x $9500 \mathrm{~m})$, kamera, tally sheet, stopwatch, Global Positioning System (GPS), alat tulis, buku identifikasi, buku panduan lapangan, Obyek yang diamati adalah Karakeristik dan Deskripsi Ordo Passeriformes di Jalan Seniman Amri Yahya Jakabaring Palembang Sumatera Selatan.

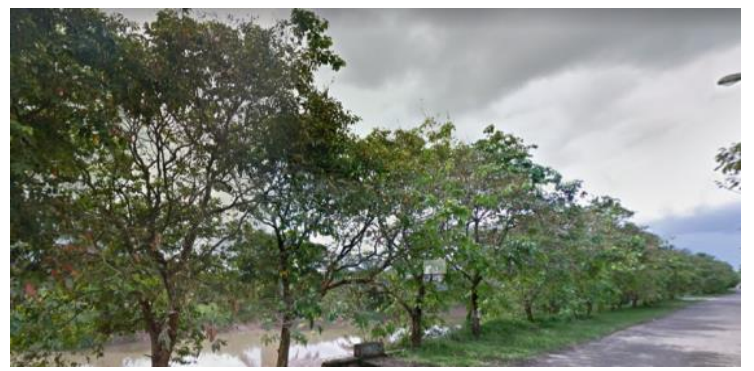

Gambar 2. Pohon bungur dilokasi pengamatan (Legertstroemia spesciosa)

(Sumber : Dokumen pribadi.2020) 
Penelitian dilakukan Selama 3 minggu Maret-April 2020. Pengamatan dilakukan pada pagi (Pukul 06.00 - 09.00 WIB) dan sore (Pukul 15.00 - 18.00 WIB). Menurut Yustian et al., (2017), Waktu Optimal melaksanakan Penagamatan adalah antara jam 06.00-09.00 WIB, sedangkan pada sore harinya jam 15.00-18.00 WIB. Pengamatan harus berjalan pada kecepatan lambat dan konsisten $(+1 \mathrm{KM} / \mathrm{Jam})$, untuk spesies yang terlihat atau terdengar dicatat nama dan spesies, jumlah individu dan waktu pengamatan.

\section{HASIL DAN PEMBAHASAN}

Hasil Pengamatan Karakteristik Dan Deskripsi Ordo Passeriformes Di Jalan Seniman Amri Yahya Jakabaring

Palembang Sumatara Selatan disajikan pada Tabel 1 berikut :

Tabel 1. Pengamatan Karakteristik Dan Deskripsi Ordo Passeriformes Di Jalan Seniman Amri Yahya Jakabaring Palembang Sumatara Selatan

\begin{tabular}{|c|c|c|c|c|c|c|c|c|c|}
\hline \multirow[t]{2}{*}{ No } & \multirow[t]{2}{*}{ Ordo } & \multirow[t]{2}{*}{ Familia } & \multirow[t]{2}{*}{ Genus } & \multirow[t]{2}{*}{ spesies } & \multirow[t]{2}{*}{ Nama lokal } & \multicolumn{3}{|c|}{ Status } & \\
\hline & & & & & & $\mathbf{E}$ & D & TD & TP \\
\hline 1 & Passeriformes & Ploceidae & Passer & Passer montanus & Gereja erasia & & & $\mathrm{V}$ & \\
\hline 2 & & Pycnonotidae & Pycnonotus & Pycnonotus aurigaster & Cucak kutilang & & & V & \\
\hline 3 & & & Pycnonotus & Pycnonotus plumosus & Merba belukar & & & V & \\
\hline 4 & & Ploceidae & Lonchura & Lonchura leucogastroides & $\begin{array}{l}\text { Pipit bondol } \\
\text { jawa }\end{array}$ & & & V & \\
\hline 5 & & Hirundinidae & Delicho & Delichon dasypus & $\begin{array}{l}\text { Layang-layang } \\
\text { rumah }\end{array}$ & & & V & \\
\hline 6 & & Silviidae & Orthotomus & Orthotomus ruficeps & Cinenen kelabu & & & $\mathrm{V}$ & \\
\hline 7 & & & Orthotomus & Orthotomus atrogularis & Cinenen belukar & & & $\mathrm{V}$ & \\
\hline 8 & & & Orthotomus & Orthotomus sutorius & Cinenen pisang & & & $\mathrm{V}$ & \\
\hline 9 & & & Prinia & Prinia flaviventris & Perenjak rawa & & & $\mathrm{V}$ & \\
\hline 10 & & Nectaninidae & Anthreptes & Anthreptes simplex & Madu polos & & & V & \\
\hline 11 & & & Nectarinindae & Anthreptes malacensis & Madu kelapa & & & & \\
\hline 12 & & & Nectariniidae & Nectarinia juengalaris & Madu sringanti & & & $\mathrm{V}$ & \\
\hline 13 & & Dicaeidae & Dicaeum & Dicaeum concolor & Cabai polos & & & $\mathrm{V}$ & \\
\hline 14 & & Chloropseidae & Aegithina & Aegithina viridissima & Cipoh jantung & & & $\mathrm{V}$ & \\
\hline
\end{tabular}

Hasil penelitian di Jalan Seniman Amri Yahya Jakabaring Palembang Sumatera Selatan. Ordo Passeriformes yang pling banyak spesies yang di temui di jalan Seniman Amri Yahya Jakabaring Sumatera Selatan. Familianya pun sangat beragam di antaranya Ploceidae, Pycnonotidae, Hirundinidae, Silviidae, Nectariniidae, Dicaeidae, dan Chloropseidae.

Pada ordo Passeriformes dengan familia Ploceidae, terdapat dua spesies yaitu Gereja arsia (Passer montanus) dan Pipit bondol jawa

(Lonchura leucogastroides). di jalan Seniman Amri Yahya Jakabaring Palembang Sumatera Selatan dua sepesies ini sangat sering di jumpai dan dari tiga titik pengamatan dua spesis ini sangat aktif bertengger, terbang, bersuara. Dua spesies ini statusnya tidak di lindungi. Pada musim panen padi dua spesies ini sebagai hama. Pada burung pipit bondol jawa sering hidup berkelompok apalagi pada musim panen padi. Dua jenis burung ini banyak menghabiskan waktu 
dalam kelompok dengan kicauanya yang ramai.

Pada ordo Passeriformes dengan familia Pycnonotidae spesies yang paling sering sekali dan sering hidup berkelompok yaitu Cucak Kutilang (Pycnonotus aurigaster), pada setiap titik satu jenis spesies ini sering bertengger dan mencari makan di atas pohon bunggur. Bersuara dan bersarang di sekitar pohon bunggur di Jalan Seniman Amri Yahya Jakabaring Sumatera Selatan. Status burung ini pun tidak di lingungi. Umumnya pemakan nektar, tetapi ada juga yang memakan serangga dan sari bunga. Sarang burung madu sangat indah, terbentuk dari rumput dan bahan lunak lainnya yang digantungkan pada pohon. Sedangkan sarang burung pijantung dijahit pada bagian bawah dedaunan, seperti daun pisang yang dijalin dengan serat jaring labalaba (MacKinnon et al., 2010).

Aves yang di temui di lapangan khususnya di Jalan Seniman Amri Yahya Jakabaring Palembang Sumatera Selatan ini, sangat beranekaragam di temui, hal ini di pengaruhi karena tumbuhan benggur tempat bersrang dan juga aliran sunggai tempat aves mencari makan dan minum di aliran sunggai serta tempat yang bisa di katakan masih alami dan tidak ada gangguan untuk burungburung bertengger di atas pohon bunggur. Keanekaragaman jenis burung dipengaruhi struktur dan Keanekaragaman jenis vegetasi. Di daerah yang keanekaragaman jenis tumbuhannya tinggi maka keanekaragaman jenis hewannya termasuk burung, tinggi pula. Keanekaragaman jenis burung di suatu wilayah dipengaruhi oleh faktor-faktor yaitu sebagai Habitat burung dipengaruh oleh ukuran luas habitat, semakin luas habitatnya, cenderung semakin tinggi keanekaragaman jenis burungnya, karena habitat bagi satwa liar secara umum berfungsi sebagai tempat untuk mencari makan, minum, istirahat dan berkembang biak.. Hal ini disebabkan oleh setiap jenis hewan hidupnya bergantung pada sekelompok jenis tumbuhan tertentu.

Keanekaragaman dan tingkat kualitas habitat di suatu lokasi mempengaruhi keanekaragaman burung. Semakin majemuk habitatnya cenderung semakin tinggi keanekaragaman jenis burungnnya. Keanekaragaman jenis burung cenderung rendah dalam ekosistem yang terkendali secara fisik dan cenderung tinggi dalam ekosistem yang diatur secara biologi (Rusmendro, 2009).

Selain burung beraktivitas mencari pakan, burung juga menghasilkan suara. Suara yang dihasilkan oleh burung berfungsi sebagai tanda atau nyayian panggilan. Nyanyian sekunder merupakan suara kedua lebih lembut atau lemah. Suara ini tidak dipergunakan dalam mempertahankan daerah teritori dan dinyanyikan oleh jenis kelamin yang berbeda dan lebih bervariasi dari pada primer song. Dibedakan menjadi empat macam suara yaitu: Whisper song, merupakan suara yang cepat dan terdengar tidak lebih $20 \mathrm{~m}$, Subsong, merupakan suara yang sangat cepat, Rehearsed song, merupakan suara yang dibunyikan oleh burung muda dan burung dewasa yang belum mencapai kesempurnaan dalam primary song dan Female song, merupakan suara yang dinyayikan oleh betina. (Wisnubudi, 2009).

\section{KESIMPULAN}

Dari hasil penelitian dapat disimpulkan :

1.Terdapat 14 Spesies di Jalan Seniman Amri Yahya Jakabaring Palembang Sumatera Selatan.

2.Terdapat Ordo Passeriformes, 7 Familia, 10 Genus dan 14 Spesies di Jalan Seniman Amri Yahya Jakabaring Palembang Sumatera Selatan.

\section{DAFTAR PUSTAKA}

Ayat, A. 2011. Burung-Burung Agroforest di Sumatera. Bogor: World Agroforestry Center.

Asep S. 2015. Keaneragaman Jenis Burung Pada Berbagaitipe Habitat Berserta Gangguannya Dihutan Penelitian Dermaga.Bogor. Jawa Bara. Junal 
Media Konversi.Vol 20. Diakses pada tanggal 17 Febuari 2020.

Burung Indonesia. 2018. Info Grafis Burung di Indonesia Tahun 2019. http://www.burung.org/2019/08/4/i nfografis-status-burung-dindonesia2019 (online). Diakses pada tanggal 5 Agustus 2019.

Iqbal, Muhammad. 2011. First Breeding record of White-crowned Forktail Enicurus leschenaulti in Sumatra Pengamat Burung Spirit of South Sumatra. Palembang. Diakses pada tanggal 17 Febuari 2020.

Iqbal, Muhammad, Catur Yuono Prasetyo, and Doni Setiawan. 2016a. The birds of Palembang Punti Kayu Recreation Forest, South Sumatra, Indonesia. Biovalentia: Biological Research Journal E-ISSN: 24771392 Vol 2, No 1. Biology of FMIPA, University of Sriwijaya Palembang. Diakses pada tanggal 17 Febuari 2020.

MacKinnon, J., Phillips, K., dan Balen, B. V. 2010. Burung-burung di Sumatera, Jawa, Bali dan Kalimantan. Rahardjaningtrah W, Adikerana A, Martodihardjo P, Supardiyono EK, Balen BS, penerjemah; Sumadipura $S$, Kartikasari A, editor. Bogor (ID): Puslitbang Biologi-LIPI.

Master Jani, Nuning Nurcahyani, Suci Natalia Dan Henny Indah Pertiwi. 2016 Keanekaragaman Jenis Burung Pada Areal Tambak Intensif Di Sumatera Selatan Dan Lampung. Biospecies Vol. 9 No.2. Jurusan Biologi Fmipa Universitas Lampung. Diakses pada tanggal 17 Febuari 2020.
Rusmendro Hasmar. (2009). Perbandingan Keanekaragaman Burung Pada Pagi dan Sore Hari di Empat Tipe Habitat di Wilayah Pangandaran Jawa Barat. Jurnal Vis Vitalis. 2(1) : 8 - 16. Diakses pada tanggal 17 Febuari 2020.

Wisnubudi G. 2009. Penggunaan Strata Vegetasi oleh Burung di Kawasan Wisata Taman Nasional Gunung Halimun-Salak Jurnal Vol. 02 No. 2. Jakarta: Fakultas Biologi Universitas Nasional, 2009. Diakses pada tanggal 17 Febuari 2020.

Yustian, Indra., Hilda Zulifli, Arum Setiawan, Doni Setiawan, Muhammad Iqbal, Ina Aprliani, Winda Indriati, Rio Firman Saputra, Hendi Sumantri, Rahmat Pratama, Catur Youno Prastyo, Deny Neberio, Guntur Pragustiandi. 2017. Panduan Survei cepat keaneragaman fauna Di Sumatera Selatan. FMIPA Universitas Sriwijaya. Palembang. 